\title{
A SURVEY ON ISLANDING DETECTION METHODS FOR GRID CONNECTED DISTRIBUTED GENERATION
}

\author{
Davheshvar Gharjare ${ }^{1}$, Mayur Katole ${ }^{2}$, Prasad Savji ${ }^{3}$ and Suresh Venkatesan ${ }^{4}$ \\ ${ }^{1-4}$ Department of Electrical Engineering, YCCE, Nagpur, India \\ Email: ${ }^{1}$ mayurkatole9@gmail.com, ${ }^{2}$ prasadsavji5@gmail.com $\}$
}

\begin{abstract}
Distributed generation is gaining importance from the last few years with the significant rise in demand of power. Distributed Generators(DG which are interconnected in parallel makes great contribution to provide clean power and improve power conditions. However, along with the advantages of grid connected system, many problems are associated with it including frequency deviation, voltage fluctuation, harmonics, etc.ne of the critical and important research topic is inherent or unintentional islanding. There is significant negative impact on DG systems due to unintended islanding. Therefore the islanding condition must be detected and the DG must be disconnected from the system to ensure safety of workers and equipment. This paper presents a survey of the islanding detection methods for grid-connected systems.
\end{abstract}

\section{Introduction}

The distributed generation by grid connected system is increasing rapidly after the advancements in various inverter topologies [1]. The systems like photovoltaic, mini type wind generation and fuel cell generation are important part of micro grid. The primary target of grid connected generation is to guarantee the grid current with same frequency and phase with grid voltage with the minimum total harmonic distortion (THD)[2-4]. Along with the harmonic distortion, the operating style of grid connected system has raised several potential safe problems like

- $\quad$ Prohibition of automatic re-closing

- Unsynchronized re-closing

- $\quad$ Failure of re-closing

- Delay of restoration

- $\quad$ Nuisance tripping of production units

- Blinding of protection

- Unintentional Islanding

One of the key problems is Islanding. According to IEEE standard, islanding is the condition in which a portion of utility system that contains both load and distributed resources remains energized while isolated from remainder of the utility system [5]. It may occur due to accidental equipment failure, operating the utility switching for maintenance, human errors, etc. The islanding can be intentional or unintentional. The unintentional islanding operation is potentially undesirable both from safety point of view as well as from power quality point of view. So the unintentional islanding must be avoided because it causes number of commercial and safety problems [7]-[9]. Out of phase reclosing may occur which may damage

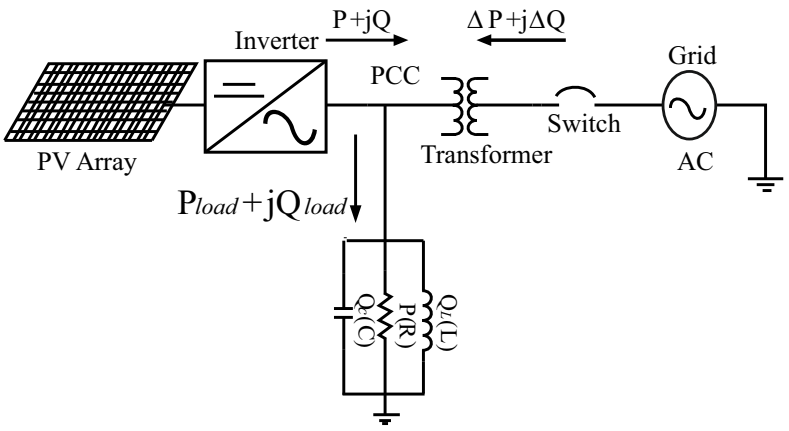

Fig. 1 : Configuration of the grid-connected PV system with local load

DG or utility equipment. This necessitates the detection of islanding condition and to disconnect the DG from the island.

As mentioned above, islanding of grid connected system occurs if the system continues to energize a section of utility grid after that section has been disconnected from the grid [10]-[13]. Consider the system configuration as shown in fig 1 in which the local load is supplied from a PV array through inverter and the grid through transformer and switch.

Equations (1) and (2) present the relationship between the PCC (Point of common coupling) parameters and the power.

$$
\begin{gathered}
P_{\text {load }}=P_{\text {inv }}+\Delta P=\frac{V_{P C C}^{2}}{R} \\
Q_{\text {load }}=Q_{\text {inv }}+\Delta Q=V_{P C C} 2\left(\frac{1}{\omega L}-\omega C\right)
\end{gathered}
$$


If the switch is closed, local load Pload and Qload is supplied from the inverter Pinv, Qinv and the grid $\Delta \mathrm{P}$, $\Delta Q$. As soon as the switch opens, the PCC voltage and frequency change rapidly until Pload and Qload is equal to Pinv and Qinv. Under/Over voltage and frequency relays are provided as the basic backup islanding detection method according to the variations in the voltage and frequency at PCC resulted by power mismatch.
Section II discusses the classification of various islanding methods. Section III discusses the remote techniques and next section discuss the local techniques. Simulation results of undervoltage and over voltage islanding method are provided in section $\mathrm{V}$ followed by summer of survey in section VI.

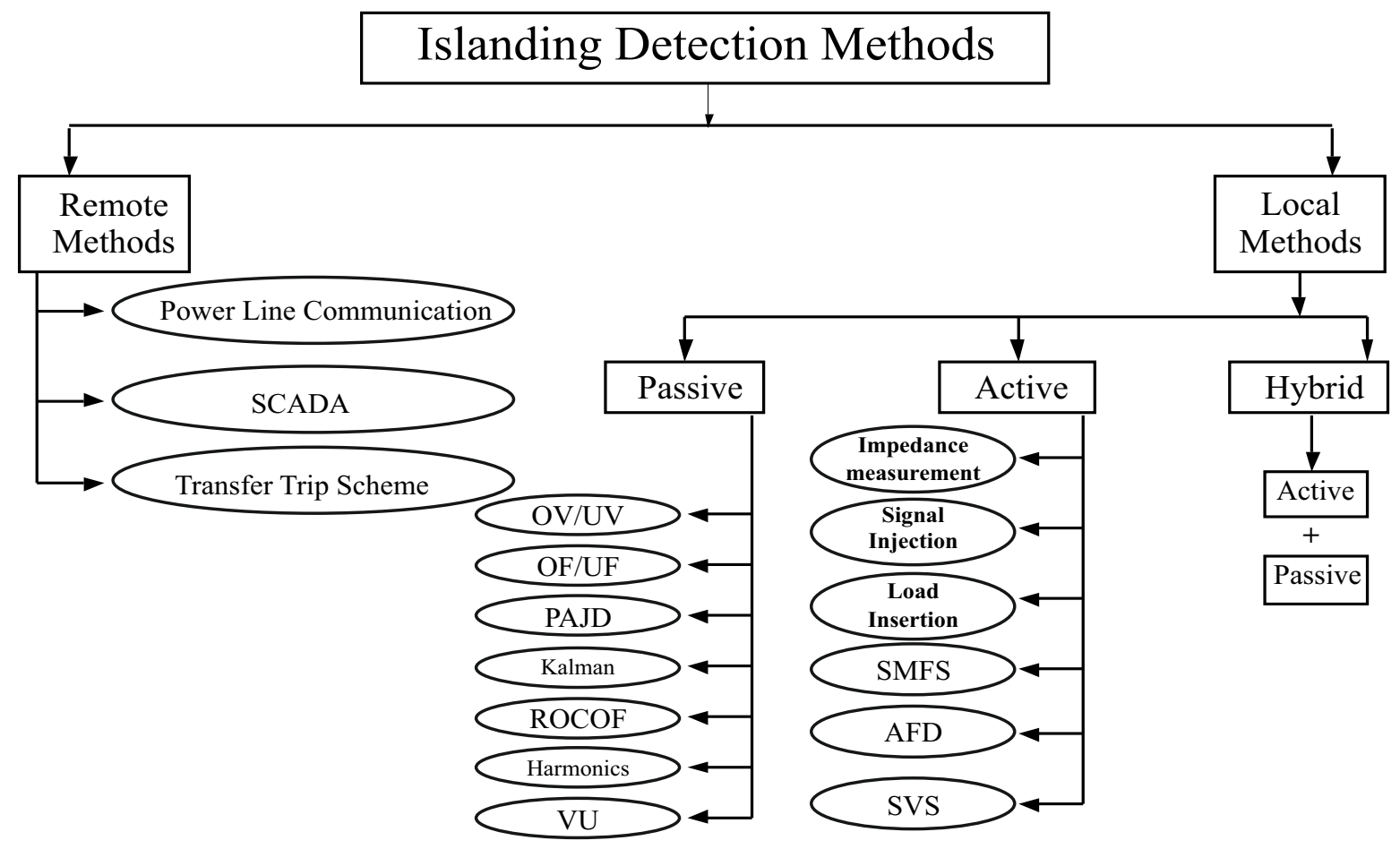

\section{Classification Of Island Detection Techniques}

An island is formed when one or more DG and the local loads becomes isolated i.e. islanded from the main grid and still remain operational. The IEEE standards 1547 [14] recommend that the islanding detection technique should be capable of functioning properly under all operating conditions and considering all types of quality issues. Island detection methods are basically classified into two categories viz. remote and local. Further classification of these methods is as shown in fig. 2.

Each of the proposed methods in fig 2, have their own weak points. The performance of islanding detection methods are evaluated on the basis of their nondetection zones [15]-[17]. NDZ (Non detection zone) is the region under which an anti-islanding technique fails to detect islanding condition. Smaller the nondetection zone better is the detection technique and vice versa. Comparing passive and active method, the
NDZ of passive methods is found more than active methods. However, active methods disturb the power quality. So, passive methods are used on larger extent. Hybrid methods aim to reduce disadvantages of active and passive method. However, islanding detection time becomes larger than other techniques.

Thus there are numerous islanding detection methods for grid connected PV system. The survey of these methods based on their effectiveness is proposed in this work.

\section{Remote Techniques}

Remote techniques are based on communication between grid and the DG. Hence these methods are also called as communication based methods. It involves the transmission of data between inverter and utility system (grid and DG). The transmitted data is used by the PV system whether to stop or continue the operation. This method provides reliable operation and has negligible NDZ but is more expensive than local ones. 


\subsection{Power line communication}

This method mainly aims on unintentional islanding. One transmitter is set at the grid side which continuously sends a signal and one receiver at the inverter receives a signal which commands the inverter. When power line signal is lost then receiver can command the inverter to cease the operation. This method has a several advantages over the local one that, it does not have NDZ. Also power quality is not affected and can be used for multi-inverter systems. Fig. 3 shows a system that includes this method.

\subsection{SCADA}

This method is also aims at unintentional islanding. This method determines the stage of all parameters related to the distribution system such as V \& I and other characteristics. There is a one central station or main station which receives the signal through communication links. After the utility or system is disconnected, if parameter is still detected from disconnected utility then we can conclude that island is occurred.

\subsection{Transfer-Trip Scheme:}

This method is different from power line communication and SCADA method as these methods monitors the states of $\mathrm{CB}$ and recloser that could island a DG system rather than normal electrical parameters like $\mathrm{V}$, I\& $\mathrm{f}$. when switching operation produces or disconnection to the substation, a central algorithm determines the islanded area. A signal is then sent to trip inverter in the islanded areas as shown in fig. 4.

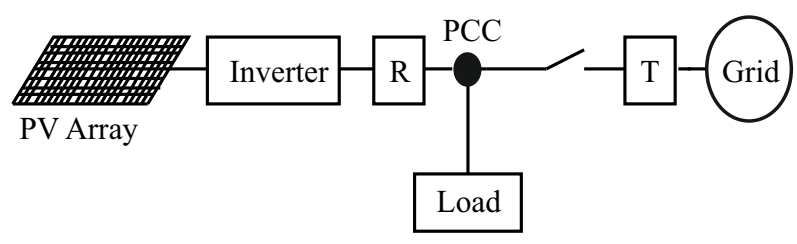

Fig. 3 : System Configuration

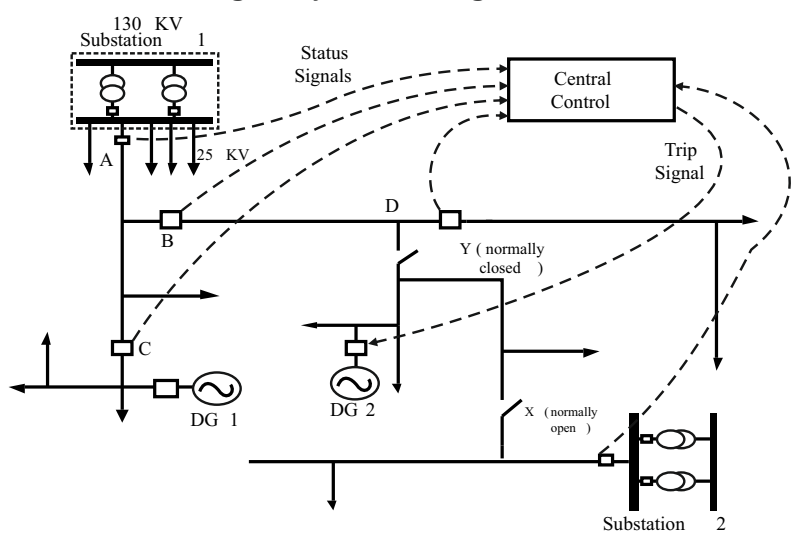

Fig. 4 : Transfer Trip Scheme
Its main limitations are cost and potential complexity because signal transmitter is needed for all possible disconnecting points in the system. Also transfer trip channel should be reliable and insensitive to noise.

\section{Local Methods}

Local methods are based on the data at the DG site and are divided into three types as explained further in paper.

\subsection{Passive methods:}

Passive methods involve monitoring of variations in different parameters like voltage, frequency, power and phase at PCC between the inverter and the utility when the island is created [18]-[19]. They are often incorporates into DGs control system and can be both economical and practical. Given fig shows the power circuit structure of DG tied to the utility grid with RLC load. In the normal operation, because the values are controlled by stiff grid with constant voltage and frequency, when islanding occurs there is a mismatch between the DG power and local load power.

Passive methods involve detection of following:

- Over-voltage/under-voltage protection (OVP/UVP) [20],[21]

- Over-frequency/Under-frequency protection (OFP/UFP) [20],[21]

- Voltage phasejump[20]-[22]

- Voltage Harmonic monitoring [21],[22]

- Current Harmonic monitoring [23]

\subsubsection{Under/Over Voltage and Under/Over Frequency}

This islanding detection technique is one of the simplest passive techniques used in islanding detection. This technique is based on the voltage change introduced in island. This method combines two methods one is Under/Over voltage and another is Under/Over frequency. Both methods can be used individually.

All grid-connected PV inverters have U/O V/F protection systems that cause the inverter to stop supplying power to the grid if the frequency or voltage at the PCC is outside of prescribed limits. These protection methods serve as islanding detection methods because the voltage or frequency will shift if there is a mismatch between the inverter output power and the power consumption. If the voltage or frequency shift drives the inverter to its detection limits, the inverter shuts down and the island has been detected [11] [24]-[27]. This method fails to detect the 
island if the power at the load is close to the power supplied by the inverter.

\subsubsection{Phase Angle Jump Detection}

When the grid is disconnected, the phase angle between the output current and the PCC voltage is load dependent [26]. If the change in the phase angle exceeds a preset threshold, the island is detected.

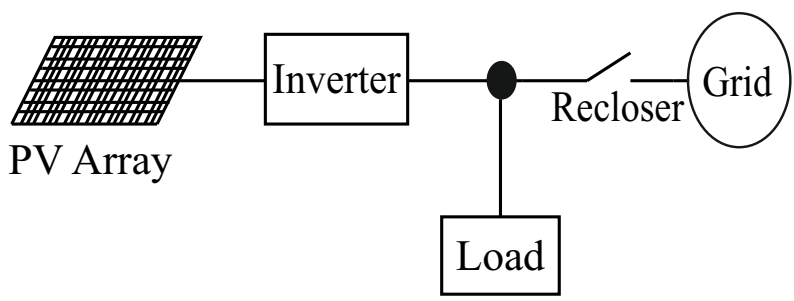

Fig. 5 : System Configuration

Phase jump detection (PJD) involves monitoring the phase difference between the inverter's terminal voltage and its output current for sudden changes [28]-[33].

A sudden change indicates that the voltage at the inverter terminals is no longer sustained and it has shifted in phase to match the phase angle of the local load. If this phase error is greater than some threshold value, the controller can de- energizes or shut down the inverter. This method has a relatively large non detection zone (NDZ) and certain loads can cause transient phase jumps that can cause nuisance trips of the inverter.

\subsubsection{Detection of Harmonics}

This approach to detect islanding is to monitor the change the THD with this method, the inverter controller monitors the total harmonic distortion (THD) of the inverter terminal voltage and shuts down the inverter if the THD exceeds a threshold [34][35]. When the island is formed, the harmonic currents produced by the inverter will flow into the load, which has much higher impedance than the utility. The harmonic currents interacting with the larger load impedance will produce larger harmonics in the PCC. These THD can be detected by the inverter, which can then assume that the DG inverter is islanding [25], [29], [36], and [15]. This method has the advantage that it does not have a non-detection zone when the local load matches the inverter output power. However, with this method it is not always possible to select a trip threshold that provides reliable islanding protection but does not lead to nuisance tripping of the inverter; also the method cannot be used when multiple inverters are connected to the island.

\subsubsection{Rate of Change of Frequency}

Rate of change of frequency (ROCOF) [38] is used for island detection in synchronous generators. In gridconnected mode, the difference between the power supplied by the synchronous generator and the load power is covered by the grid so that the system frequency remains constant. In island mode, there is a power imbalance because of grid disconnection. This power imbalance causes a frequency change be used to detect the islanding. If the power imbalance is small, the frequency changes slowly. Thus ROCOF can be used to improve the island detection.

ROCOF is considered to be most commonly used measure, but it has a serious drawback that relays that are sensitivity to network disturbance leads to nuisance tripping.

\subsubsection{Voltage Unbalance}

Basically the method is to monitor the unbalance three phase output voltage of the inverter. Due to the changes in network parameters of load after loss of the main source, unbalance voltage varies even though load varies by small amount. Voltage unbalance is taken over one fundamental period; voltage unbalance variation describes how much the voltage unbalance deviates from steady state and normal loading condition.

The main drawback of this method is that voltage unbalance can be measured only in multiphase systems, so this method is not applicable for single phase system. Another drawback is it has large NDZ due to which this method combines with THD of current. When the island occurs, load condition on DG suddenly changes in respect to normal operating condition. This method calculates voltages (line-toline) of all this three phases at every sampling time. If this method does not lead to shutdown of DG other monitoring parameter like THD in current is evaluated. As a result it provides good selectivity.

\subsubsection{Kalman filter}

A Kalman filter is implemented in [38] for island detection. That technique is based on energy mismatch between the estimated third and fifth harmonics and the real ones.

\subsection{Active Methods}

When the utility grid is connected the stability of grid prevents changes in amplitude frequency and/or phase. When system is islanded, these voltage, current or frequency disturbances that are injected into the supply system will perturb the load circuit. Islanding conditions are thereby detected if the disturbances 
have caused a change in voltage, current or frequency at the PCC. Thus active method relies on deliberately introducing disturbances to the utility grid and then monitoring the response to determine if the utility grid with its inherently stable frequency, voltage and impedance, is still connected [39]. Active method presents a smaller NDZ than passive ones. So generally speaking, active methods are more effective than passive methods. However they negatively affect power quality [19], [20], [36] based on following parameters:

- Output power variation either real or reactive [21], [44].

- Active frequency drift or frequency shift up/down [15], [22], [40]-[43].

- $\quad$ Sliding mode or slip-mode frequency shift [15], [22], [43].

- $\quad$ Sandia frequency shift or accelerated frequency drift or active frequency drift with positive feedback [22], [42].

- Impedance measurement [15], [21], [22].

- Detection of impedance at a specific frequency or monitoring of harmonic distortion [15], [45].

- $\quad$ Sandia voltage shift [15].

- Frequencyjump [15]

\subsubsection{Impedance Measurement}

Impedance measurement techniques attempt to detect the change in inverter output circuit impedance that occurs when the low impedance distribution network is disconnected [14], [30], and [34],[46][49].The primary advantage of the impedance measurement method is its extremely small NDZ. But its effectiveness decreases in the multi-inverter case unless all the inverters using this method are somehow synchronized. It is necessary to set an impedance threshold, below which the impedance detection method assumes that the grid is still connected.

\subsubsection{Signal injection}

Using this method the inverter injects a known signal into the output current and monitors the terminal voltage response [29], [46], [50]. One signal that can be injected is a current harmonic of a specific frequency different than the line frequency. But in this method multiple inverters injecting the same signal may cause false trips or otherwise interfere with each other.

\subsubsection{Load insertion}

When the recloser is opened the inverter can connect load impedance across its output terminals and monitor changes that occur [30], [31]. For example, a capacitor can be inserted across the output, as shown in Fig. 2 [51].

\subsubsection{Sliding Mode Frequency Shift:}

The principle of the sliding mode frequency shift (SMS) method is to force the frequency of inverter output up/down by controlling the starting phase angle of the inverter current [11], [44], [36], [39], [42].

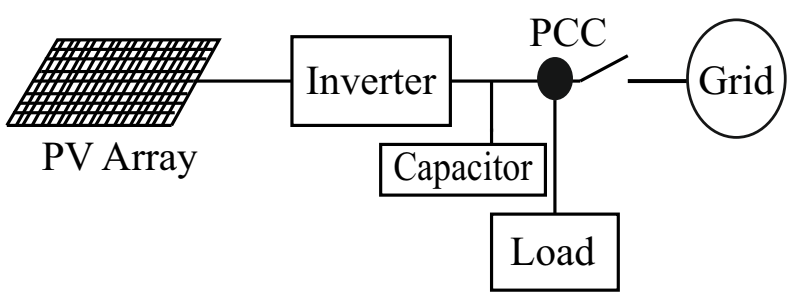

Fig. 6 : System Configuration

In the SMS method, the current-voltage phase angle of the inverter, instead of always being controlled to be zero, is made to be a function of the frequency of the voltage at the PCC [20], [32], [52]-[54].

\subsubsection{Active Frequency Drift}

The principle of the active frequency drift (AFD) or frequency bias method is to force the frequency of inverter output up/down by using positive feedback to accelerate the frequency of the inverter current [11], [44], [52], [56]. In this method, by injecting into the PCC a current waveform that is slightly distorted changes the frequency [36],[53]-[55].

\subsubsection{Sandia Voltage Shift}

Sandia Voltage Shift (SVS) applies positive feedback to the current or active power regulation control loop of the inverter to cause the inverter terminal voltage to rapidly shift to the under/over voltage detection threshold if the distribution network is not present to maintain the voltage [14],[57]. The positive feedback introduces instability that drives the inverter terminal voltage towards one of the voltage limits. This method is easy to implement using a micro-controller and when implemented with SFS, this method presents a small NDZ. A weakness of this method is that it requires a very small reduction in output power quality. Because of this, penetration levels of inverters using the method may have to be kept low.

\subsection{Hybrid methods}

Hybrid islanding detection techniques combine the 
principles of active and passive techniques so that merging active and passive techniques the shortcoming of both of them can be prevailed. They aim to reduce negative effects on grid introduced by active ones while maintaining NDZ smaller than passive one. For example, in hybrid method one can detect the islanding condition by measuring the PCC voltage and current signal as by passive method. However, it evaluates a high frequency components injected by PV DG inverter to detect the islanding condition as done by active method.

This islanding detection technique is effectual even when there is a close mismatch between the DG power generation and the power absorbed by the load. In a hybrid islanding detection method [15] which uses total harmonic distortion and continuous feedback and selection is presented.

\subsubsection{PF and VU Technique}

Voltage Unbalance is also considered as part of the hybrid method. It uses the positive feedback as the active technique and VU as the passive technique.

Here the three-phase voltages are continuously monitored at the DG terminals, and VU is calculated for each DG. THD is not used in this hybrid technique because during the simulations, it was found that $\mathrm{VU}$ was more sensitive to disturbances than THD. Any disturbance applied to DGs, e.g., as a result of random load changes (switching) or islanding, could result in a spike in VU. To discriminate between the VU spike due to islanding and that due to other reasons, another feature has been added to this technique. Whenever a VU spike above the set threshold is observed, then the frequency set point of the DG is gradually lowered from 60 to $59 \mathrm{~Hz}$ in one second [37].Maximum permissible voltage is given by

$$
V U_{\text {spike }}=35 \times V U_{\text {avg }}
$$

Where $\mathrm{VU}_{\text {avg }}$ is the average value of $\mathrm{VU}$ over the past one second.

\section{Simulation Results Of Undervoltage \& Overvoltage Based Islanding Conditions}

The results which are shown below demonstrate the condition during which islanding will be detected. As shown in Fig. 7, Fig. 8, Fig. 9 the grid is disconnected at $0.6 \mathrm{sec}$ and conditions of under voltage, over voltage and equal voltage are detected.

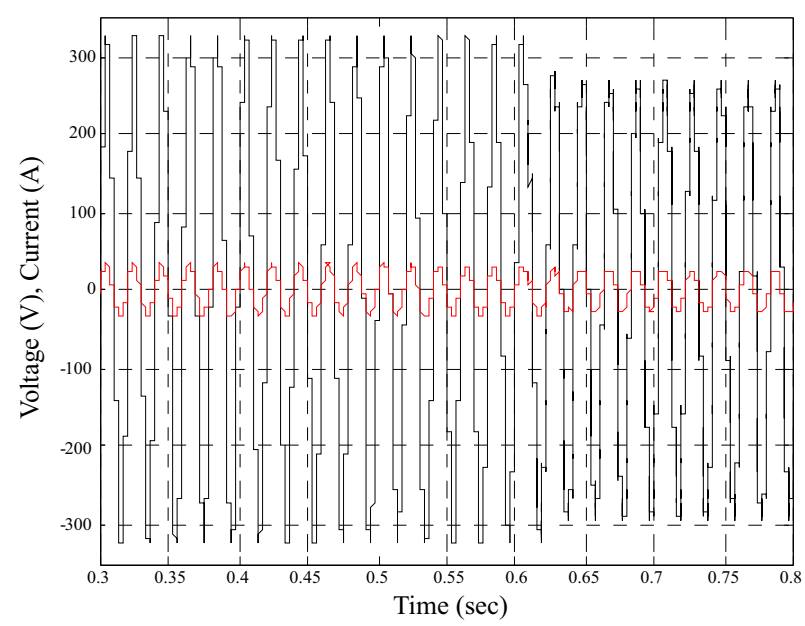

Fig. 7 : Under voltage condition

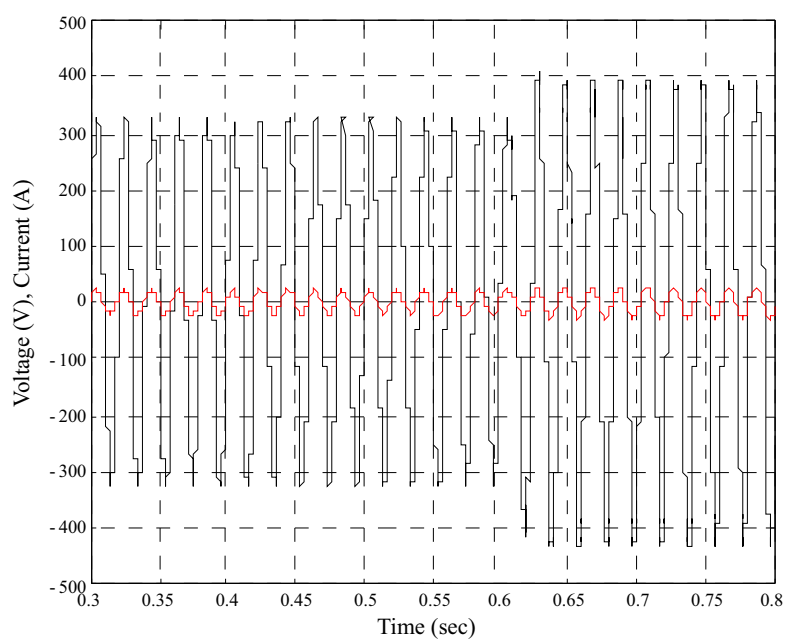

Fig. 8 : Overvoltage condition

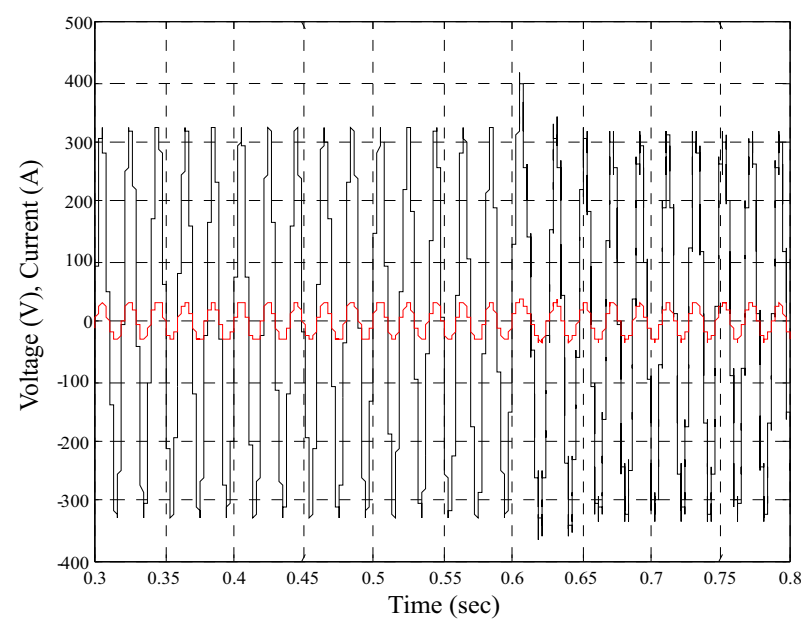

Fig. 9 : Equal voltage condition 


\section{Conclusion}

Various methods and circuits are developed to detect an islanding condition for inverter based DG. They can be distinguished mainly in 2 groups i.e., remote and local, thereafter local techniques can be further classified into active, passive and hybrid. The main concerns about choosing method are power quality and NDZ.

The remote techniques comes with a negligible NDZ and high speed operation but more expensive than local techniques. Passive methods produce significant NDZ but do not have any power quality effect. An active method develops a reduced NDZ but grid quality quietly affected due to disturbance injection. Hybrid methods combine the advantages of active and passive methods but are somewhat complex. Also the time required for detection is much higher than other techniques.

\section{References}

[1] F. Blaabjerg, Z. Chen, and S.B. Kjaer, "Power electronics as efficient interface in dispersed power generation systems", IEEE Trans. on Power Electronics, Vol. 19, No. 5, September 2004, p. 1184-1194.

[2] E. Koutroulis and F. Blaabjerg, "Design optimization of transformerless grid-connected PV inverters including reliability," IEEE Trans. Power Electron., vol. 28, no. 1, pp. 325-335, Jan. 2013.

[3] I. Abdalla, J. Corda, and L. Zhang, "Multilevel DC-link inverter and control Algorithm To Over ComethePVpartialshading,"IEEETrans.Power Electron.,vol.28, no. 1, pp. 14-18, Jan. 2013.

[4] H.Hu, S.Harb, N.Kutkut, I.Batarseh, andZ.J.Shen, "Areviewofpower decoupling techniques for microinverters with three different decoupling capacitor locationsinPVsystems, IEEETrans.PowerElectron" vol.28, no. 6, pp. 2711-2726, Jun. 2013.

[5] IEEE recommend practice for utility interface of PV system, IEEE standard 929-2000.

[6] Stevens, J.R.Bonn, J.Gimn and sigifredoGonzalezet, "Development and testing of an Approach to an Antiislanding in utility-interconnected PV system," PV System Applications Department Sandia National Laboratories, 2000.

[7] Ropp, M.E., M.Bogovic and A. Rohatigi, "Analysis and Performance Assessment of the Active Frequency Drift Method of Islanding Prevention," IEEE Transaction Energy Conversion, vol.14, pp.810-816, sep.1999.

[8] Treitas.W., W. Xu. , C.M. Affonso, Zhengyu Huang, "Comparative Analysis Between ROCOF and Vector Surge Relays For DG Applications," IEEE Transaction, Power Delivery, vol.20, pp.1315-1324, April, 2005.
[9] IEEE Std. 929-2000, "IEEE Recommended Practice for Utility Interface of Photovoltaic (PV) Systems," IEEE Standards Coordinating Committee 21 on Fuel Cells, Photovoltaics, Dispersed Generation, and Energy Storage, April 2000.

[10] Jeraputra, C., "Investigation of Islanding detection Schemes for Utility Interconnection of Distributed Fuel Cell Powered Generations," PhD. Dissertation, Texas A\&M University, 2004.

[11] Hernandez-Gonzalez, G.; et al., "Current injection for active islanding detection of electronically-interfaced distributed resources," Power Delivery, IEEE Transactions on, vol. 21 no. 3, pp. 1698 - 1705, July 2006.

[12] Ranade, Satish J., et al., "Likelihood of Islanding in Distribution Feeders with Photovoltaic Generation," Power Engineering Society General Meeting IEEE, pp. 1-6, June 2007.

[13] IEEE Std. 1547, "Standard for Interconnecting Distributed Resources with Electric Power Systems," 2003.

[14] W. Bower and M. Ropp, Evaluation of islanding detection methods for utility-interactive inverters in photovoltaic systems, Sandia Nat. Labs., Albuquerque, NM, USA, Sandia Rep. SAND2002-3591.

[15] W. Bower and M. Ropp, "Evaluation of islanding detection methods for photovoltaic utility-interactive power systems," International Energy Agency (IEA), Albuquerque, NM, USA, Task V Rep. IEA-PVPS T5-09, Mar. 2002.

[16] Z.Ye, A.Kolwalkar, Y.Zhang, P.Du, andR.Walling, "Evaluationofanti- islanding schemes based on nondetection zone concept," IEEE Trans. Power Electron., vol. 19, no. 5, pp.1171-1176, Sep. 2004.

[17] Samuelsson, 0. et al., "Islanding detection and connection requirements," Power Engineering Society General Meeting, IEEE, pp. 1-6, June 2007.

[18] Jou, H.L.; et al., "Virtual inductor-based islanding detection method for grid-connected power inverter of distributed power generation system," Renewable Power Generation, vol. 1 no. 3, pp. 175 - 181, September 2007.

[19] W. Bower and M Ropp, "Evaluation of islanding detection methods for photovoltaic utility-interactive power systems", IEA Task V Report IEA-PVPS T5-09, March 2002.

[20] H. Kobayashi, K. Takigawa and E. Hashimoto, "Method for preventing islanding phenomenon on utility grid with a number of small scale PV systems", Record of. IEEE Photovoltaic Specialists Conference 1991, p. 695-700.

[21] M.E. Ropp, M. Begovic and A. Rohatgi, "Prevention of islanding in grid-connected photovoltaic systems", Progress in Photovoltaics: Research and Applications, 7, 39-59, 1999. 
[22] M. Francesco De, L. Marco, D. A. Antonio, and P. Alberto, "Overview of Anti-Islanding Algorithms for PV Systems. Part I: Passive Methods", Proc. of EPE-PEMC, 2006, pp. 1878-1883.

[23] Zhihong Ye; et al., "Evaluation of anti-islanding schemes based on nondetection zone concept," Power Electronics, IEEE Transactions on, vol. 19 no. 5, pp. 1171-1176, Sept. 2004.

[24] Menon, V.; et al., "A Hybrid Islanding Detection Technique Using Voltage Unbalance and Frequency Set Point", Power Systems, IEEE Transactions on, vol. 22 no. 1, pp. $442-448$, Feb. 2007.

[25] Vieira, J.C.M.; et al., "Performance of frequency relays for distributed generation protection," Power Delivery, IEEE Transactions on, vol. 21 no. 3, pp. 1120 1127, July 2006.

[26] Zhang Chunjiang; et al., "A Novel Active Islanding Detection Method of Grid-connected Photovoltaic Inverters Based on Current- Disturbing," IPEMC '06, vol. 3, pp. 1-4, August 2006.

[27] UL 1741, "Inverter, converters, and controllers for use in independent power systems," 2002.

[28] Zhang Chunjiang; et al., "A Novel Active Islanding Detection Method of Grid-connected Photovoltaic Inverters Based on Current- Disturbing," IPEMC '06, vol. 3, pp. 1-4, August 2006.

[29] Zeineldin, H.; et al., "Intentional islanding of distributed generation," PES 2005, vol. 2, pp. 1496 1502, June 2005.

[30] Ropp, M., et al., "Prevention of islanding in gridconnected photovoltaic systems," Progress in Photovoltaic: Research and Applications, 1999.

[31] Singam, B.; et al., "Assessing SMS and PJD Schemes of Anti- Islanding with Varying Quality Factor," PECon 2006, pp. $196-201$.

[32] De Mango, F; et al., "Overview of Anti-Islanding Algorithms for PV Systems. Part I: Passive Methods," EPE-PEMC 2006, pp. 1878 - 1883, Aug. 2006.

[33] Guiliang Yin, "A Distributed Generation Islanding Detection Method Based on Artificial Immune System," Transmission and Distribution Conference and Exhibition, 2005 IEEE/PES, pp.1 - 4.

[34] Jun Yin; et al., "Recent developments in islanding detection for distributed power generation," LESCOPE 2004 ,pp. $124-128$.

[35] Lopes, L. A. C.; et al., "Islanding Detection Assessment of Multi- Inverter Systems With Active Frequency Drifting Methods," Power Delivery, IEEE Transactions on, vol. 23, pp. 480 - 486, Jan. 2008.

[36] Jeraputra, C., "Investigation of Islanding detection Schemes for Utility Interconnection of Distributed Fuel Cell Powered Generations," PhD. Dissertation, Texas A\&M University, 2004.
[37] Vivek Menon and M. Hashem Nehrir, Senior Member, IEEE, "A Hybrid Islanding Detection Techniques Using Voltage Unbalance and Frequency Set Point" IEEE TRANSACTIONS ON POWER SYSTEMS, VOL. 22, NO. 1, FEBRUARY 2007.

[38] Huili Sun; et al., "Analysis and comparison of islanding detection methods using a new load parameter space," IECON 2004, vol. 2, pp. 1172 - 1177, Nov. 2004.

[39] Liserre, M.; et al., "An Anti-Islanding Method for SinglePhase Inverters Based on a Grid Voltage Sensorless Control," Industrial Electronics, IEEE Transactions on, vol. 53 no. 5, pp. 1418 -1426, Oct. 2006.

[40] A.M.Massoud, K.H.Ahmed, S.J.Finney, B.W.Williams, "HarmonicDistortion Based Island Detection Technique for Inverter-Based DG”, IRT Renewable Power Generation, 17 apr-2009.

[41] M. A. Eltawil, and Z. Zhao, "Grid-connected photovoltaic power systems: Technical and potential problems-A review", Renewable and Sustainable Energy Reviews, Volume 14, Issue 1, pp. 112-129. January 2010.

[42] M.E. Ropp, M. Begovic and A. Rohatgi, "Analysis and performance assessment of the active frequency drift method of islanding prevention", IEEE Trans. on Energy Conversion, Vol. 14, No. 3, September 1999, p. 810-816.

[43] S. Yuyama, T. Ichinose, K. Kimoto, T. Itami, T. Ambo, C. Okado, K. Nakajima. S. Hojo, H. Shinohara, S. Ioka and M. Kuniyoshi, "A high-speed frequency shift method as a protection from islanding phenomena of utility interactive PV systems", Solar Energy Materials and Solar Cells, Vol. 35, 1994, p. 477-486.

[44] P. Sanchis, L. Marroyo and J. Coloma, "Design methodology for the frequency shift method of islanding prevention and analysis of its detection capability", Progress in Photovoltaics: Research and Applications 2005, Vol.13 no. 5, p. 409-428.

[45] G.A. Smith, P.A. Onions and D.G. Infield, "Predicting islanding operation of grid connected PV inverters", IEE Proceedings- Electrical Power Applications, Vol. 147, No 1, January 2000, p. 1-5.

[46] L.A.C. Lopes and H. Sun, "Performance assessment of active frequency drifting islanding detection methods", IEEE Trans. on Energy Conversion, Vol. 21, No. 1, March 2006, p. 171-180.

[47] Z. Ye, L. Li, L. Garces, C. Wang, R. Zhang, M. Dame, R. Walling and N. Miller, "A new family of active antiislanding schemes based on DQ implementation for grid-connected inverters", in Record of IEEE PESC 2004, Aachen, Germany, p. 235-241.

[48] Ciobotaru, Mihai; et al., "Online grid impedance estimation for single-phase grid-connected systems using PQ variations," PESC 2007, pp. 2306 - 2312, June 2007. 
[49] Ciobotaru, Mihai; et al., "On-line grid impedance estimation based on harmonic injection for gridconnected PV inverter," ISIE 2007, pp. 2437 - 2442, June 2007.

[50] Ropp, M.; et al., "Simulation and Experimental Study of the Impedance Detection Anti-Islanding Method in the Single-Inverter Case," Photovoltaic Energy Conversion, Conference Record of the 2006 IEEE 4th World Conference on, vol. 2, pp. 2379-2382.

[51] Bertling, F.; et al., "A novel converter integrable impedance measuring method for islanding detection in grids with widespread use of decentral generation," SPEEDAM 2006, pp. $503-507$.

[52] Karimi, H.; et al., "Negative-Sequence Current Injection for Fast Islanding Detection of a Distributed Resource Unit," Power Electronics, IEEE Transactions, vol. 23 no. 1, pp. $298-307,2008$.

[53] Xu, W.; et al., "An Assessment of DG Islanding Detection Methods and Issues for Canada," Report CETCVarennes 2004-074, CANMET Energy Technology Centre, July 2004.

[54] Zheng Shi-cheng; et al., "Study on Photovoltaic Generation System and Its Islanding Effect," ICIEA 2007, pp. 2328-2332, May 2007.
[55] Yongzheng Zhang; et al., "Design and Compliance of Frequency Drifting Islanding Detection Methods with the IEEE Standard 1547.1," CCECE 2007, pp. 1574 1577, April 2007.

[56] Byunggyu Yu; et al., "A Robust Anti-islanding Method for Grid- Connected Photovoltaic Inverter," Photovoltaic Energy Conversion, Conference Record of the 2006 IEEE 4th World Conference on, vol. 2, pp. 2242 - 2245, May 2006.

[57] Liu, Furong; et al., "Analysis and optimization of active frequency drift islanding detection method," APEC 2007, pp. $1379-1384$.

[58] Wang, Hui; et al., "Experimental Investigation on Non Detection Zones of Active Frequency Drift Method for Anti-islanding," IECON 2007, pp. 1708 - 1713, Nov. 2007.

[59] John, V.; et al., "Investigation of anti-islanding protection of power converter based distributed generators using frequency domain analysis," Power Electronics, IEEE Transactions on, vol. 19 no. 5, pp. $1177-1183$, Sept. 2004. 